\title{
Bcl-2 Family Gene Expression in Oropharyngeal Squamous Cell Carcinoma
}

\author{
Jeremiah Tracy ${ }^{1}$, Ian Mukand-Cerro ${ }^{2}$, Miriam O’Leary ${ }^{1}$, Nora Laver ${ }^{2} \&$ Richard O. Wein ${ }^{1}$ \\ ${ }^{1}$ Department of Otolaryngology - Head and Neck Surgery, Tufts Medical Center, Boston, MA, USA \\ ${ }^{2}$ Department of Pathology and Laboratory Medicine, Tufts Medical Center, Boston, MA, USA \\ Correspondence: Jeremiah Tracy, Tufts Medical Center, 800 Washington Street, Boston, MA 02111, USA. Tel: \\ 1-617-636-5496. E-mail: jtracy@tuftsmedicalcenter.org
}

Received: December 29, 2013 Accepted: January 28, $2014 \quad$ Online Published: April 1, 2014

doi:10.5539/cco.v3n1p11

URL: http://dx.doi.org/10.5539/cco.v3n1p11

\begin{abstract}
Dysregulation of apoptosis is a well-described characteristic of malignant transformation. In the field of colorectal cancer, the Bcl-2 family of apoptotic proteins has been characterized as a marker of poor prognosis and response to current chemotherapeutic agents. In head and neck squamous cell carcinoma (SCC), the role of Bcl-2 and associated apoptosis proteins is less well understood.

Immunohistochemical staining was performed in order to assess for expression of Bcl-2, Bcl-Xl, and Bax in surgical or biopsy specimens of patients treated for oropharyngeal SCC from 1999-2009. This data was correlated with the clinical outcomes of recurrence and/or persistence of disease.

Our findings on 20 specimens are presented. By establishing the association between these pathologic biomarkers and clinical characteristics of disease, more accurate diagnostic and prognostic tools will be available in the care of head and neck cancer patients.
\end{abstract}

Keywords: head and neck cancer, oropharyngeal squamous cell carcinoma, Bcl-2, squamous cell carcinoma

\section{Introduction}

Inhibition of the process of apoptosis is seen in most epithelial malignancies including squamous cell carcinoma (SCC) of the head and neck (Friedman et al., 1997). The B-cell lymphoma-2 (Bcl-2) gene is associated with a family of proteins involved in the regulation of apoptosis (Hockenbery, Nunez, Milliman, Schreiber, \& Korsmeyer, 1990). This includes anti-apoptotic proteins such as Bcl-2 and Bcl-Xl and pro-apoptotic proteins such as Bax and Bad (Jackel, 1999).

Dysregulation of Bcl-2 gene products, initially described as an inhibitor of apoptosis in B-cell lymphoma, has also been associated with other epithelial malignancies such as colorectal carcinoma. Subsequent studies demonstrated the over-expression of Bcl-2 in a subset of head and neck SCC tumors (Friedman et al., 1997; Jordan, Catzavelos, Barrett, \& Speight, 1996). Since that time, several studies have suggested that Bcl-2 over-expression is associated with aggressive histopathologic features and advanced initial TNM tumor staging (Jordan et al., 1996; Pignataro et al., 1997; Sharma, Sen, Mathur, Bahadur, \& Singh, 2004). Recent studies have suggested that tumors that overexpress Bcl-2 are less responsive to treatment with chemoradiation therapy and that Bcl-2 expression is an independent predictor of poor outcome (Trask et al., 2002; Nix, Cawkwell, Patmore, Greenman, \& Stafford, 2005; Michaud et al., 2009; Shah et al., 2004; Nichols et al., 2010).

The aim of this study was to correlate the expression of the Bcl-2 gene products with clinical outcomes in oropharyngeal SCC. The role of Bcl-Xl and Bax in head and neck SCC has yet to be elucidated definitively. In addition this study represents the first investigation into the relationship between Bcl-2 and the clinical course of patients that underwent surgery as part of their care as opposed to those treated with chemoradiation alone.

\section{Materials and Methods}

Tissue-banked surgical specimens were used in order to investigate this correlation. Consecutive oropharyngeal SCC specimens that were obtained in the period from January 1, 1999 to December 31, 2009 were included. Experimental methods were reviewed and approved by the Tufts Medical Center Institutional Review Board.

Initially, the specimens were stained using immunohistochemical (IHC) techniques to assess for expression of 
three Bcl-2 family proteins: Bcl-2, Bcl-Xl, and Bax. Two independent researchers from the department of Pathology reviewed the slides for gene product expression.

Next, a review of the electronic medical record (EMR) was performed. Patient data recorded includes: age, TNM classification at presentation, smoking history, HPV status, and treatment modality used. Please see Table 1. Treatment plan was decided by institutional Multidisciplinary Head \& Neck Board; involving otolaryngologist/head \& neck surgeons, radiation oncologists, and medical oncologists.

Table 1. Patient characteristics

\begin{tabular}{ccccccc}
\hline Patient & Age & Sex & Smoking & $\begin{array}{c}\text { TNM } \\
\text { Classification }\end{array}$ & $\begin{array}{c}\text { Treatment } \\
\text { modality }\end{array}$ & $\begin{array}{c}\text { Persistence/ } \\
\text { Recurrence }\end{array}$ \\
\hline 1 & 70 & F & Y & T1N1M0 & CRT & N \\
2 & 50 & M & Y & T2N0M0 & Surgery/RT & Y \\
3 & 67 & M & N & T4N2bM0 & Surgery/CRT & N \\
4 & 71 & M & N & T4N0M0 & CRT & Y \\
5 & 47 & M & Y & T2N2bM0 & Surgery/RT & N \\
6 & 54 & M & N & T1N0M0 & Surgery & Y \\
7 & 56 & M & N & T4N0M0 & Surgery/RT & N \\
8 & 58 & M & N & T3N1M0 & CRT & Y \\
9 & 53 & M & N & T2N2M0 & Surgery/CRT & N \\
10 & 58 & M & N & TxN1M0 & Surgery/RT & Y \\
11 & 47 & M & N & T1N3M0 & Surgery/RT & N \\
12 & 49 & M & Y & T1N2bM0 & Surgery/RT & N \\
13 & 51 & M & N & T2N0M0 & Surgery/RT & N \\
14 & 58 & M & Y & T3N2M0 & CRT & N \\
15 & 57 & M & Y & T1N2bM0 & CRT & Y \\
16 & 81 & M & Y & T3N0M0 & RT & Y \\
17 & 74 & M & Y & T1N0M0 & RT & Y \\
18 & 47 & M & Y & T1N1M0 & CRT & N \\
19 & 63 & M & N & T1N2bM0 & CRT & N \\
20 & 64 & M & N & T2N0M0 & CRT & N \\
\hline
\end{tabular}

CRT: concurrent chemoradiation therapy; Surgery/RT: surgical treatment with adjuvant radiation; Surgery/CRT: surgical treatment with adjuvant concurrent chemoradiation; RT: primary radiation treatment.

\section{Results}

The results of the first 20 specimens stained are presented below. The median age of patients was 58 years. The majority of patients (19/20) were male. At the time of diagnosis, 14 of the 20 patients had advanced stage (overall stage III/IV) disease. Approximately 50\% (9/20) of patients had disease recurrence or persistence after initial treatment documented. The median duration of follow-up of patients within the group was 26 months.

On IHC testing, 9 specimens were found to express Bcl-2. Bcl-Xl and Bax were expressed in 6 and 11 specimens respectively. A semi-quantitative method was used to assess gene expression. Each specimen was examined by two independent surgical pathologists, who assigned a number indicating the number of cells in the specimen expressing staining. Values were assigned to categorize specimens as either "positive" or "negative" in order to more easily discuss the findings and begin to compare findings. Bcl-2 expression was considered positive if any staining was observed. Bcl-Xl was considered positive if $>10 \%$ of cells examined were found to express gene product staining; and Bax (which was expressed in nearly all specimens) was considered positive for $>90 \%$ staining. Recurrence/persistence rates by gene expression are listed in Table 2 below. 


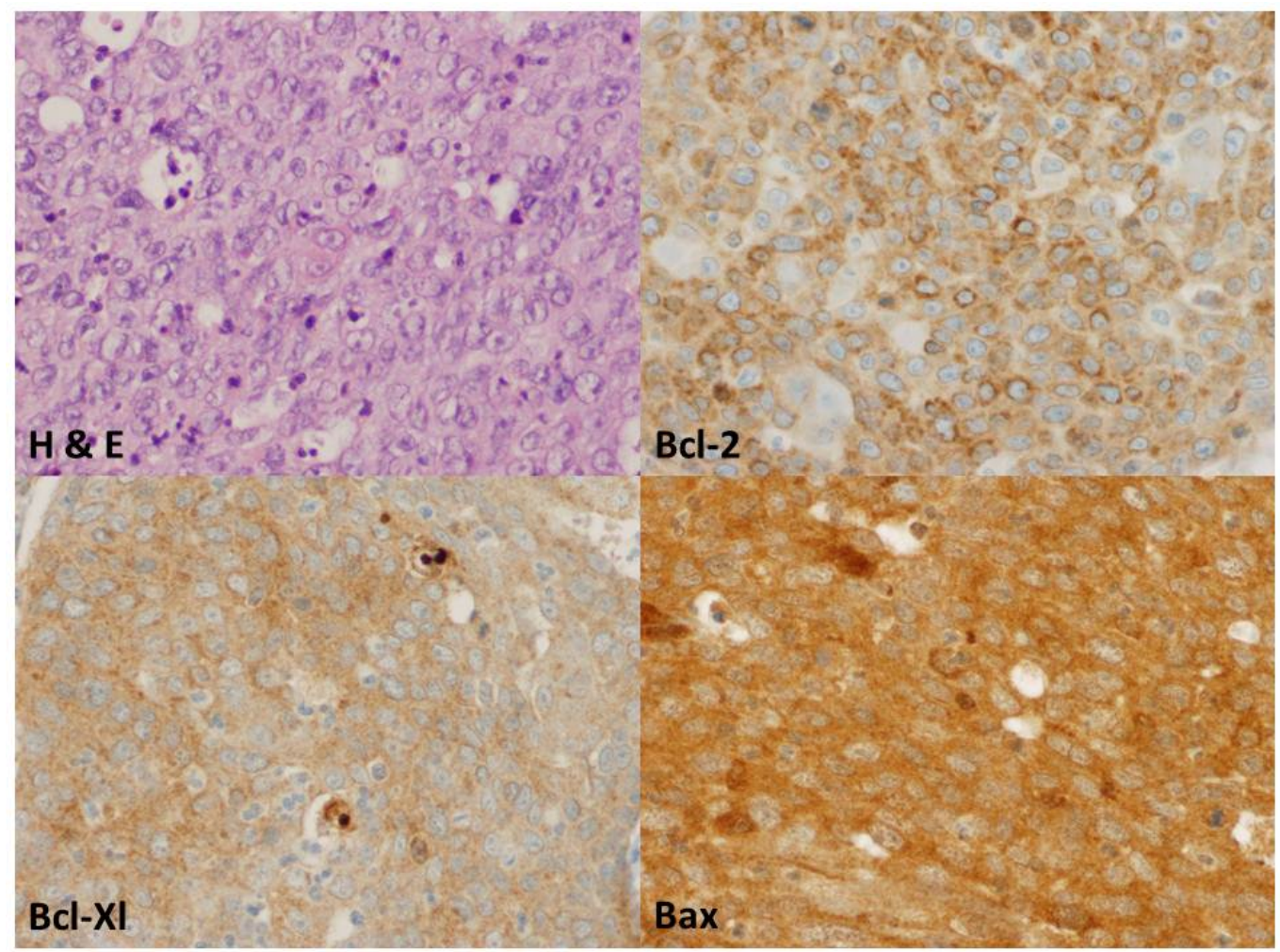

Figure 1. High-power (40x) microscopy demonstrating hematoxylin and eosin as well as Bcl-2, Bcl-Xl, and Bax IHC staining

Table 2. Expression of Bcl-2 family proteins

\begin{tabular}{|c|c|c|c|c|c|c|c|}
\hline & $\mathrm{n}$ & Median Age & Smoking & HPV+ & Stage I/II & Stage III/IV & Recurrence/Persistence \\
\hline \multicolumn{8}{|l|}{$\mathrm{Bcl}-2$} \\
\hline Negative & 11 & 64 & 7 & 2 & 4 & 7 & 6 \\
\hline Positive & 9 & 53 & 2 & 8 & 2 & 7 & 3 \\
\hline \multicolumn{8}{|l|}{ Bcl-Xl } \\
\hline Negative & 14 & 58 & 7 & 5 & 5 & 9 & 8 \\
\hline Positive & 6 & 59 & 2 & 5 & 1 & 5 & 1 \\
\hline \multicolumn{8}{|l|}{ Bax } \\
\hline Negative & 9 & 58 & 4 & 1 & 4 & 5 & 7 \\
\hline Positive & 11 & 54 & 5 & 9 & 2 & 9 & 2 \\
\hline
\end{tabular}

\section{Discussion}

The field of head and neck cancer has seen dramatic changes as molecular biology has identified new targets for highly specific chemotherapeutic agents (Le Tourneau \& Siu, 2008). The role of Bcl-2 in the malignant transformation of colorectal cancers is well established and Phase II clinical trials evaluating the effectiveness of Bcl-2 inhibitors are currently being performed (Vogler, Dinsdale, Dyer, \& Cohen, 2009). Only recently has Bcl-2 been identified as a factor in the etiology of head and neck SCC; and the role that Bcl-2 family proteins play is still not entirely understood. There exists conflicting data regarding whether Bcl-2 expression is associated with more or less aggressive disease (Nichols et al., 2010; Wu et al., 2012).

Bcl-2 expression in SCC at the oropharyngeal subsite has been reported and is currently the subject of large-scale prospective studies (Wu et al., 2012). The role of other Bcl-2 family proteins in head \& neck cancer has not yet been determined. Ito et al. (1999) demonstrated that low Bax expression was associated with advanced tumor stage. Barber et al. (2013) found a statistically significant correlation between Bcl-Xl overexpression and nodal disease at presentation in a recent study utilizing tissue microarrays. The association of 
these gene products with disease outcome and response to treatment has not been studied.

There is currently a great deal of interest in the field of head and neck cancer in identifying biomarkers which might aid in predicting disease prognosis. Bcl-2 inhibitors are currently in phase II clinical trials for use in advanced colorectal cancer (Vogler et al., 2009). Biomarker panels have already been applied to head \& neck cancer in terms of guiding prognosis; HPV-status, Bcl-2, and other biomarkers were used to categorize patients as high, moderate, or low risk. Future studies will likely explore the possibility of de-intensifying chemoradiation protocols for patients with "low-risk" tumor biology (Wu et al., 2012).

Our data reflects some interesting trends. Nearly all of the patients whose tumors expressed Bax had recurrence or persistence. Further, Bcl-2 expression correlated with HPV positivity in 8 of 9 cases. The expression of Bcl-2 and HPV-positivity has previously been shown to be independent (Nichols et al., 2010). The sample size of this study is too small to make speculations regarding a correlation between gene expression and disease outcomes.

Bcl-2 gene expression is associated with oropharyngeal squamous cell carcinoma, and seems to be a negative prognostic indicator (Trask et al., 2002, Nichols et al., 2010). The role of other Bcl-2 family proteins has yet to be elucidated. Eventually, such information may guide treatment decisions such as tailoring chemotherapeutic regiments or decreasing radiation dosing. The Bcl-2 family of apoptosis proteins is intriguing candidates for additional investigation. Further research into the role these genes play in tumor growth and malignant transformation is warranted.

\section{References}

Barber, B. R., Biron, V. L., Klimowicz, A. C., Puttagunta, L., Côté, D. W., \& Seikaly, H. (2013). Molecular predictors of locoregional and distant metastases in oropharyngeal squamous cell carcinoma. J Otolaryngol Head Neck Surg, 42(1), 53. http://dx.doi.org/10.1186/1916-0216-42-53

Friedman, M., Grey, P., Venkatesan, T. K., Bloch, I., Chawla, P., Caldarelli, D. D., \& Coon, J. S. (1997). Prognostic significance of Bcl-2 expression in localized squamous cell carcinoma of the head and neck. Ann Otol Rhinol Laryngol, 106(6), 445-50.

Hockenbery, D., Nunez, G., Milliman, C., Schreiber, R. D., \& Korsmeyer, S. J. (1990). Bcl-2 is an inner mitochondrial membrane protein that blocks programmed cell death. Nature, 348, 334-6. http://dx.doi.org/10.1038/348334a0

Ito, T., Fujieda, S., Tsuzuki, H., Sunaga, H., Fan, G., Sugimoto, C, ... Saito, H. (1999). Decreased expression of Bax is correlated with poor prognosis in oral and oropharyngeal carcinoma. Cancer Lett, 140(1-2), 81-91.

Jackel, M. (1999). Spontaneous apoptosis in laryngeal squamous cell carcinoma Is independent of bcl-2 and bax protein expression. Cancer, 85, 591-9. http://dx.doi.org/10.1002/(SICI)1097-0142(19990201)85:3<591::AI D-CNCR9>3.0.CO;2-F

Jordan, R., Catzavelos, G., Barrett, \& A., Speight, P. (1996). Differential expression of bcl-2 and bax in squamous cell carcinomas of the oral cavity. Eur $J$ Cancer, 32B, 394-400. http://dx.doi.org/10.1016/S0964-1955(96)00033-4

Kumar, B., Cordell, K. G., Lee, J. S., Worden, F. P., Prince, M. E., Tran, H. H., .. Carey, T. E. (2008). EGFR, p16, HPV titer, Bcl-xL and p53, sex, and smoking as indicators of response to therapy and survival in oropharyngeal cancer. J Clin Oncol, 26, 3128-37. http://dx.doi.org/10.1200/JCO.2007.12.7662

Le Tourneau, C., \& Siu, L. L. (2008). Molecular-targeted therapies in the treatment of squamous cell carcinomas of the head and neck. Current Opinion in Oncology, 20, 256-63. http://dx.doi.org/10.1097/CCO.0b013e3282f9b575

Michaud, W. A., Nichols, A. C., Mroz, E. A., Faquin, W. C., Clark, J. R., Begum, S., ... Rocco, J. W. (2009). Bcl-2 blocks cisplatin-induced apoptosis and predicts poor outcome following chemoradiation treatment in advanced oropharyngeal squamous cell carcinoma. Clin Cancer Res, 15(5), 1645-54. http://dx.doi.org/10.1158/1078-0432.CCR-08-2581

Nichols, A. C., Finkelstein, D. M., Faquin, W. C., Westra, W. H., Mroz, E. A., Kneuertz, P., ... Rocco, J. W. (2010). Bcl-2 and human papilloma virus 16 as predictors of outcome following concurrent hemoradiation for advanced oropharyngeal cancer. Clin Cancer Res, 16(7), 2138-46. http://dx.doi.org/10.1158/1078-0432.CCR-09-3185

Nix, P., Cawkwell, L., Patmore, H., Greenman, J., \& Stafford, N. (2005). Bcl-2 expression predicts radiotherapy failure in laryngeal cancer. British Journal of Cancer, 92(12), 2185-89. http://dx.doi.org/10.1038/sj.bjc.6602647 
Pignataro, L., Carboni, N., Pagliari, A. V., Capaccio, P., Ottaviani, F., \& Pruneri, G. (1997). Bcl-2 expression is related to poor differentiation and advanced clinical stage in laryngeal squamous cell carcinoma. $J$ Chemother, 7(9), 115-6. http://dx.doi.org/10.1179/joc.1997.9.2.115

Shah, N. G., Trivedi, T. I., Tankshali, R. A., Goswami, J. V., Jetly, D. H., Shukla, S. N., ... Verma, R. J. (2009). Prognostic significance of molecular markers in oral scc: a multivariate analysis. Head Neck, 31, $1544-56$. http://dx.doi.org/10.1002/hed.21126

Sharma, H., Sen, S., Mathur, M., Bahadur, S., \& Singh, N. (2004). Combined evaluation of expression of telomerase, survivin, and anti-apoptotic Bcl-2 family members in relation to loss of differentiation and apoptosis in head and neck cancers. Head Neck, 26(8), 733-40.

Trask, D. K., Wolf, G. T., Bradford, C. R., Fisher, S. G., Devaney, K., Johnson, M., ... Wicha, M. (2002). Expression of Bcl-2 family proteins in advanced laryngeal squamous cell carcinoma: correlation with response to chemotherapy and organ preservation. Laryngoscope, 112, 638-44. http://dx.doi.org/10.1097/00005537-200204000-00009

Vogler, M., Dinsdale, D., Dyer, M. J., \& Cohen, G. M. (2009). Bcl-2 inhibitors: small molecules with a big impact on cancer therapy. Cell Death and Differentiation, 16, 360-367. http://dx.doi.org/10.1038/cdd.2008.137

Wu, Y., Posner, M. R., Schumaker, L. M., Nikitakis, N., Goloubeva, O., Tan, M., ... Cullen, K. J. (2012). Novel biomarker panel predicts prognosis in human papillomavirus-negative oropharyngeal cancer. Cancer, 118(7), 1811-7. http://dx.doi.org/ 10.1002/cncr.26485

\section{Copyrights}

Copyright for this article is retained by the author(s), with first publication rights granted to the journal.

This is an open-access article distributed under the terms and conditions of the Creative Commons Attribution license (http://creativecommons.org/licenses/by/3.0/). 